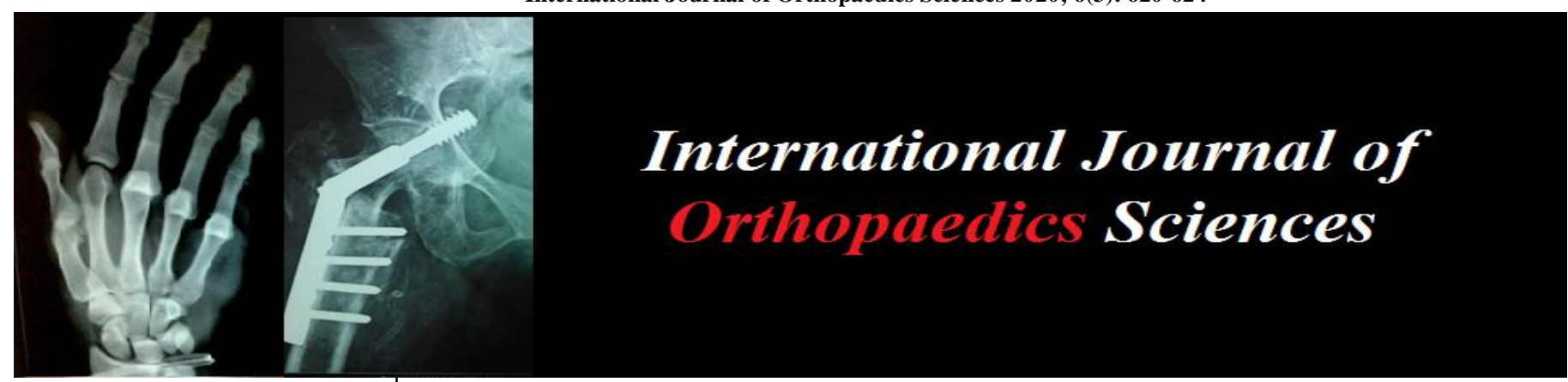

E-ISSN: 2395-1958

P-ISSN: 2706-6630

IJOS 2020; 6(3): 620-624

(C) 2020 IJOS

www.orthopaper.com

Received: 08-05-2020

Accepted: 10-06-2020

\section{Harshal Hurkat}

(Santokba Durlabhji Memorial

Hospital, Jaipur, Rajasthan, India

\section{Jayant Sen}

(Santokba Durlabhji Memorial Hospital, Jaipur, Rajasthan,

India

Prateek Goyal

(Santokba Durlabhji Memoria Hospital, Jaipur, Rajasthan, India
Corresponding Author: Harshal Hurkat

(Santokba Durlabhji Memorial Hospital, Jaipur, Rajasthan,

India

\section{Predictors of functional outcome of surgical management in proximal tibia fractures}

\author{
Harshal Hurkat, Jayant Sen and Prateek Goyal
}

DOI: https://doi.org/10.22271/ortho.2020.v6.i3j.2260

\section{Abstract}

Background: Tibia plateau fractures constitute about $1 \%$ of all fractures and complex bicondylar fractures constitute $30 \%$ of all Tibial plateau fractures. These fractures pose an inherent difficulty in treatment due to the extent of soft tissue damage, fracture comminution, instability, displacement of articular fragments and increased risk of compartment syndrome. Present study was carried to find out functional outcome in different fracture management technique.

Material and methods: A total 25 cases of tibial plateau fracture treated with different implants from April 2019 to September 2019 in Santokba Durlabhji Memorial Hospital were followed for minimum of 6months. Patients less than 18 years and more than 60 years of age, Compound trauma and fractures due to pathological conditions were excluded. Functional outcome was measured using Rasmussen's grading system at 6month follow up.

Results: Maximum study subjects (36\%) were in age group of $31-40 \mathrm{yrs}, 80 \%$ had road traffic accidents as a mode of injury. $32 \%$ were of type V Schatzker fracture classification. $48 \%$ subjects were operated by ORIF with LCP Plating, 24\% subjects were operated by LCP Plating plus CC screw, $20 \%$ were operated by bicondylar plating, $8 \%$ were operated by $\mathrm{CC}$ screw. Most of the subjects with plates had either excellent or good outcome.

Conclusion: ORIF with plating gives excellent to good functional outcome with minimal soft tissue complications.

Keywords: Predictors of functional surgical management proximal tibia plateau fractures

\section{Introduction}

There are different types of proximal tibia fractures which include articular depression, condylar displacement, metaphyseal fracture extension. Tibial plateau fractures constitute about $1 \%$ of all fractures and complex bicondylar fractures constitute $30 \%$ of all Tibial plateau fractures ${ }^{[1]}$

The fracture patterns are very complex and may involve medial, lateral or both the tibial plateaus. All fractures have different morphology and require individualized treatment. Knowledge about type of trauma, either high energy or low energy, meniscal tears and ligament injuries helps in determining the further mode of management ${ }^{[1]}$.

The complex Tibial plateau fractures resulting from direct forces due to high-velocity injuries are classically described as "explosion or shattered" fractures. These fractures pose an inherent difficulty in treatment due to the extent of soft tissue damage, fracture comminution, instability, displacement of articular fragments and increased risk of compartment syndrome. Forclosed management of these complex fractures with cast bracing and traction generally has been ineffective in reducing and maintaining the congruency of the articular surface and axial alignment leading to mal-union and secondary degenerative arthritis ${ }^{[2]}$.

Various modes of treatment are available for treatment of tibial fractures which include definitive external fixation, dual plating, but the best treatment method still remains controversial ${ }^{[1]}$. Different surgical approaches and various modes of fracture fixation have been developed to treat these fractures. These techniques of open reduction and internal fixation of individual tibial plateau helps maintain anatomic articular congruity and restoration of mechanical alignment and allows early mobilization of knee joint. Sometimes, these techniques of open reduction and internal fixation, especially done through injured soft tissues 
have been associated major wound complications ${ }^{[1]}$.

Although many treatment pushed back into history and some has came with improvement and some newly developing approaches, never implants and plates, there are some pros and cons of each one over other and no standard treatment yet to decided so present study was carried out to find out functional outcome in different fracture management technique.

\section{Material and methods}

A prospective observational study was carried out for duration of April 2019 to September 2019 among subjects with proximal tibial fracture at Santokba Durlabhji Memorial Hospital which is well known for treatment of complex tibial fracture. Patients less than 18 years and more than 60 years of age, Compound trauma and fractures due to pathological conditions were excluded. Fractures were classified according to Schatzker fracture classification to decide treatment plan. After stabilizing patient in casualty, detailed history was taken and complete general and local examination of patient was carried out. Patients having shock were treated in Intensive care unit with prompt resuscitative measures. After stabilizing general condition of patient, X-rays were taken [AP, oblique, lateral and stress views if ligament injury was suspected]. According to the type of fracture, amount of displacement and depression treatment plan was decided.

All surgeries were performed under $\mathrm{C}$-arm intensifier. Fractures fixation was done with close reduction with percutaneous screw fixation or MIPPO fixation or by open reduction and internal fixation. Indication for Single column and dual column fixation was decided according on the fracture pattern. The implants used for fixation were locking $3.5 \mathrm{~mm}, 4.5 \mathrm{~mm} \mathrm{~T}$ plate \& $4.5 \mathrm{~mm} \mathrm{~L}$ plate, $4.5 \mathrm{~mm}$ locking hockey plate, $3.5 \mathrm{~mm}$ RAFT plate $4.5 \mathrm{~mm}$ cortical screws and $6.5 \mathrm{~mm}$ cannulated and non-cannulated cancellous screws.

Postoperative immobilization was done with an above knee slab. The suture removal was done on 14th postoperative day. Intravenous antibiotics were given till 3rd postoperative day, after that oral antibiotics were given for further 7 days. Postoperative X-ray immediately after surgery was taken.

Follow up

The first follow up after 2 weeks of suture removal was done, during this visit surgical scar and knee range of motion was started. During second follow up after 6 weeks check X-ray was advised to see signs of fracture union or displacement if present.

At the third follow up after 3 months check X-ray was advised to see status of boneunion. Patients were advised partial weight bearing and than full weight bearing According to clinical and radiological signs of union. After that patients were advised for followed up at 6 months, on these visits anatomical and functional evaluation was done by using the Rasmussen scoring system.

\section{Results}

A total of 25 subjects with proximal Tibia fracture were included in study with age range of 20-58yrs and mean age of $42.12 \pm 11$ yrs. Maximum study subjects $(36 \%)$ were in age group of 31-40yrs and M:F was 5.2:1. Among study subjects $80 \%$ had road traffic accidents as a mode of injury. $32 \%$ were of type V Schatzker fracture classification. Associated injury was found among 5 subjects. Maximum (48\%) were operated using LCP plates; $24 \%$ were operated using LCP plates plus screw $8 \%$ were operated with CC screw. only $2(8 \%)$ subjects had infection as early complication and $4(16 \%)$ had stiffness as late complication. Maximum 13 (52\%) had good, 8(32\%) had excellent, 2(8\%) each had fair and poor functional outcome during follow up. Most of the 23 (92\%) subjects had fracture union. Most of the subjects in different age group i.e. 20-30yrs, 31-40yrs, 41-50yrs and 51-60yrs had either excellent or good outcome. Among young subjects (20-30yrs) $25 \%$ and among elderly subjects (51-60yrs) $16.7 \%$ had poor functional outcome.

Table 1: Baseline study characteristics

\begin{tabular}{|c|c|c|}
\hline Study variables & Frequency & Percent \\
\hline \multicolumn{3}{|l|}{ Age group } \\
\hline $20-30 y r s$ & 4 & 16 \\
\hline 31-40yrs & 9 & 36 \\
\hline 41-50yrs & 6 & 24 \\
\hline 51-60yrs & 6 & 24 \\
\hline \multicolumn{3}{|l|}{ Gender } \\
\hline Female & 4 & 16 \\
\hline Male & 21 & 84 \\
\hline \multicolumn{3}{|l|}{ Fracture type } \\
\hline $\mathrm{I}$ & 2 & 8.0 \\
\hline II & 4 & 16.0 \\
\hline III & 5 & 20.0 \\
\hline IV & 3 & 12.0 \\
\hline V & 8 & 32.0 \\
\hline VI & 3 & 12.0 \\
\hline \multicolumn{3}{|l|}{ Surgery performed } \\
\hline ORIF with LCP Plating & 12 & 48.0 \\
\hline ORIF with LCP plus CC Screw & 6 & 24.0 \\
\hline ORIF with bicondylar Plating & 5 & 20.0 \\
\hline CC Screw & 2 & 8.00 \\
\hline \multicolumn{3}{|l|}{ Implant } \\
\hline Plates & 17 & 68 \\
\hline LCP Plates plus Screw & 6 & 24 \\
\hline CC Screw & 2 & 8 \\
\hline
\end{tabular}

Table 2: Functional outcome among study group

\begin{tabular}{|c|c|c|}
\hline Functional outcome & Frequency & Percent \\
\hline Excellent & 8 & 32 \\
\hline Good & 13 & 52 \\
\hline Fair & 2 & 8 \\
\hline Poor & 2 & 8 \\
\hline Total & 25 & 100 \\
\hline
\end{tabular}

Table 3: Relation between type of fracture and functional outcome

\begin{tabular}{|c|c|c|c|c|c|}
\hline \multirow{2}{*}{ Type of fracture } & \multicolumn{4}{|c|}{ Functional outcome } & \multirow{2}{*}{ Total } \\
\cline { 2 - 5 } & Excellent & Good & Fair & Poor & 2 \\
\hline I & $2(100 \%)$ & 0 & 0 & 0 & 4 \\
\hline II & $3(75 \%)$ & $1(25 \%)$ & 0 & 0 & 5 \\
\hline III & $2(40.0 \%)$ & $3(60.0 \%)$ & 0 & 0 & 3 \\
\hline IV & 0 & $3(100 \%)$ & 0 & 0 & 8 \\
\hline V & 0 & $6(75 \%)$ & $1(12.5 \%)$ & $1(12.5 \%)$ & 3 \\
\hline VI & $1(33.3 \%)$ & 0 & $1(33.3 \%)$ & $1(33.3 \%)$ & 25 \\
\hline Total & $8(32.0 \%)$ & $13(52.0 \%)$ & $2(8.0 \%)$ & $2(8.0 \%)$ & \\
\hline
\end{tabular}


Fig 1: Instrument Set comprising various plates

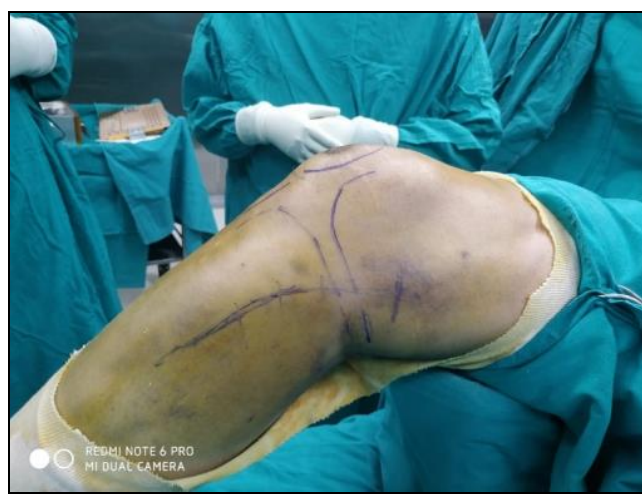

Fig 2: Position of patient with bolster

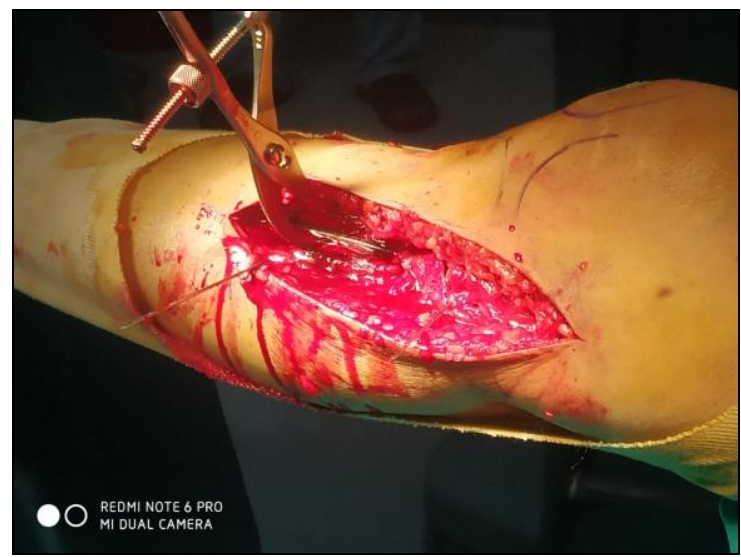

Fig 5: Lateral completion plate being fixed after reduction

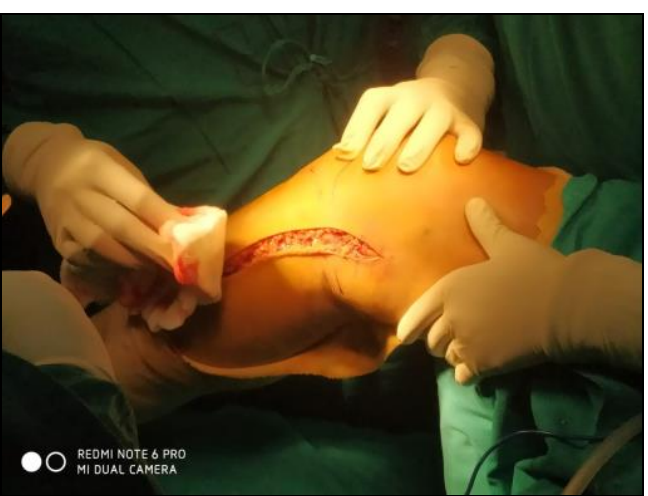

Fig 3: Careful soft tissue dissection

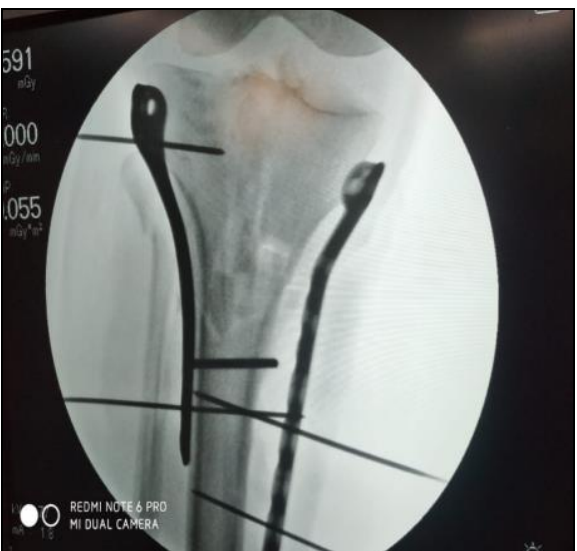

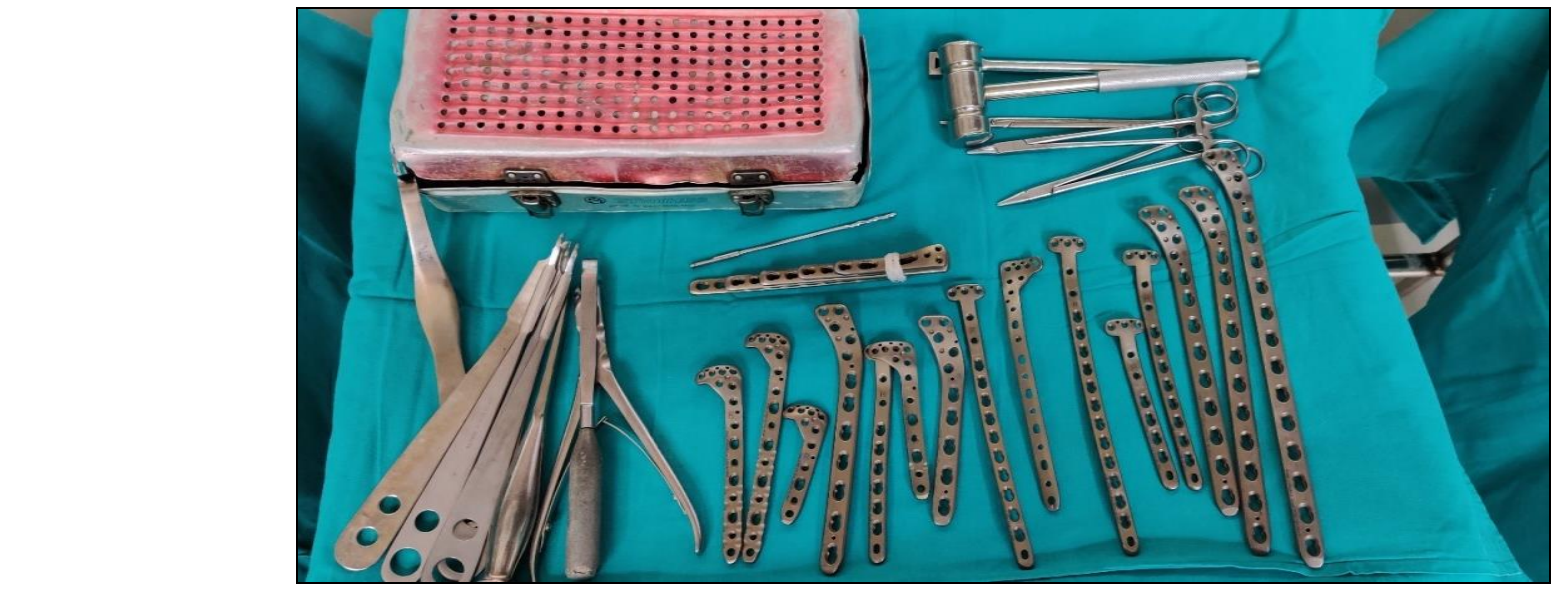



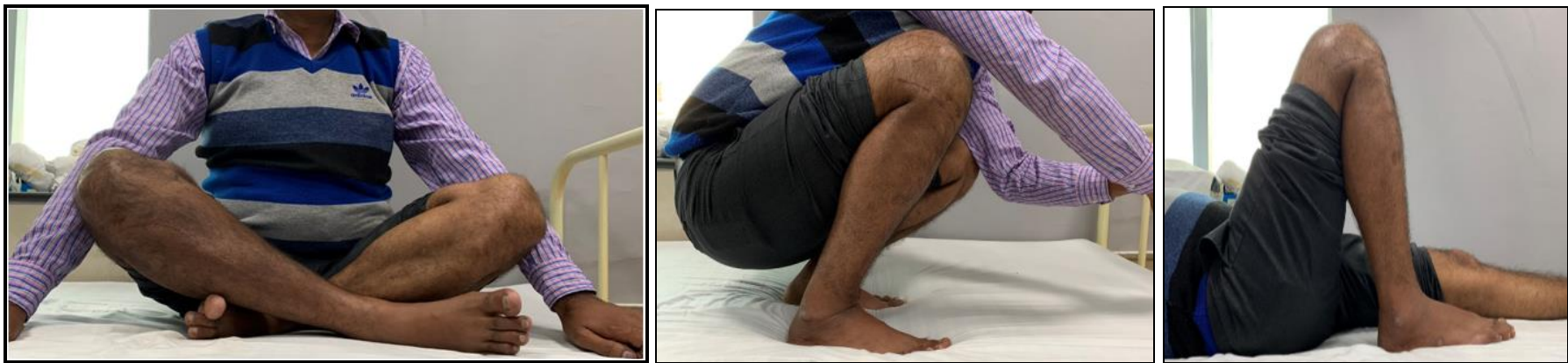

Fig 8: Clinical photographs of patient after 6 months

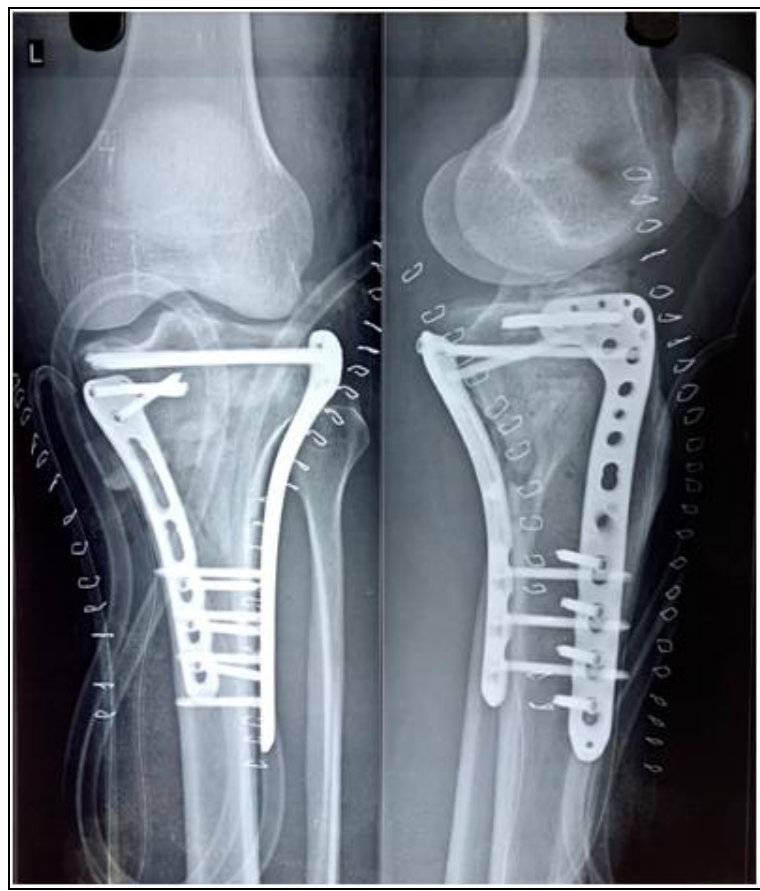

Fig 9: Immediate post op x-ray

\section{Discussion}

Proximal tibial plateau involvement is one of the most common intra-articular fractures. They occur as a result of either indirect trauma causing coronal fracture pattern or direct trauma causing axial compressive patterns. This comprises of $1 \%$ of all fractures ${ }^{[1]}$. The fracture patterns are very complex and may involve medial, lateral or both the tibial plateaus. All fractures have different morphology and require individualized treatment. Knowledge about type of trauma, either high energy or low energy, meniscal tears and ligament injuries helps in determining the further mode of management ${ }^{[1]}$.

In our study, maximum subjects $(36 \%)$ were in age group of $31-40$ years, mean age of $42.12+11$ years and most commonly

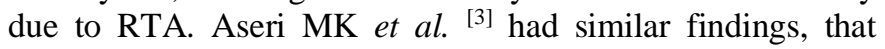
maximum incidence of proximal tibial fracture in the productive age populace i.e., $31-40$ years $(36.67 \%)$ with mean age 39.03 years and RTA as the most common cause. Seppo [4] also showed age incidence of 20-60 years with an average of 39.8 years, Neil Rohra et al. ${ }^{[5]}$ found that the tibial plateau fractures were most commonly due to RTA and between the age group 24 to 65 years (mean age 46.20 years), similar with our study.

Our study had $84 \%$ male and $16 \%$ female participants and M: F 5.2:1. Neil Rohra et al. ${ }^{[4]}$ found out of 34 patients, $29(85.29 \%)$ were males and $5(14.71 \%)$ were females. Aseri MK et al. [3] found majority of the patients were male $(83.33 \%)$.

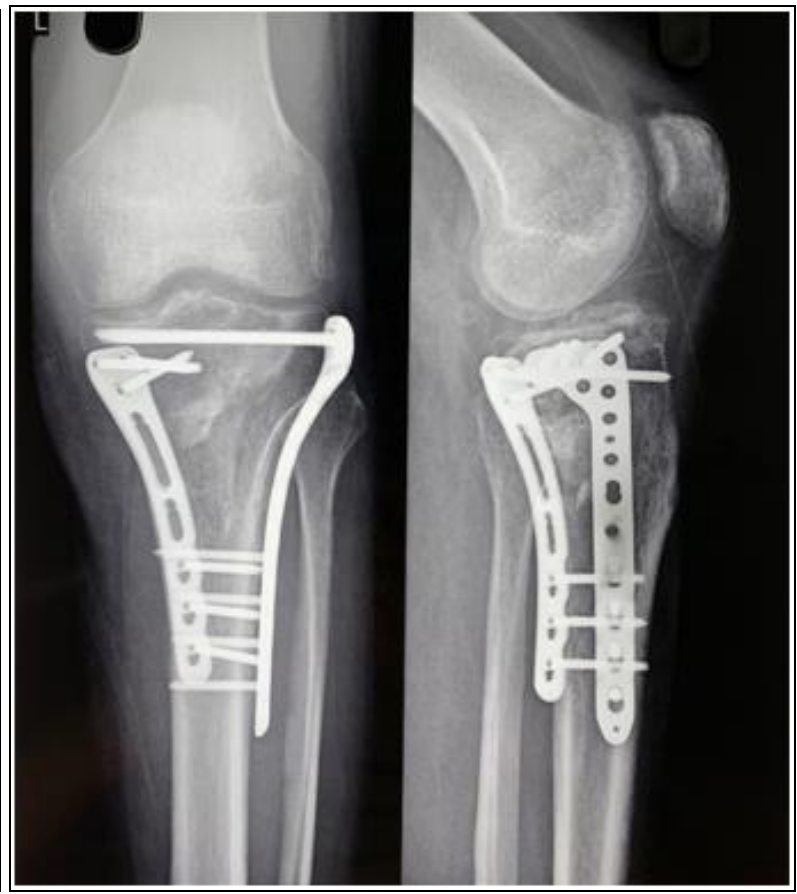

Fig 10: Follow up X-ray after 6 months

In our study $32 \%$ were of type $\mathrm{V}$ fracture, $12 \%$ each were type VI \& type IV and $52 \%$ had left sided fractures. Neil Rohra et al. ${ }^{[4]}$ found that Type V were 13 (38.24\%) and type VI were $21(61.76 \%)$ and there was a slight right sided predominance $(55.88 \%)$, compared to left side (44.12\%). Aseri MK et al. ${ }^{[3]}$ found that most of the patients were of type V (9 cases) and type VI (7cases) Schatzker's classification $(53.33 \%)$

In spite of associated injuries and complications, we found that $52 \%$ had good, $32 \%$ had excellent, $8 \%$ each had fair and poor functional outcome among study group during follow up. Study by Aseri MK et al. ${ }^{[3]}$ had30\% excellent result, $60 \%$ good result (overall $90 \%$ acceptable result), $10 \%$ fair result in terms of functional outcome. Neil Rohra et al. ${ }^{[4]}$ found that 24 patients $(70.59 \%)$ had excellent, 8 patients $(23.53 \%)$ had good and 1 patient $(2.94 \%)$ each of poor and fair functional Knee Society Score.

In present study $32 \%$ subjects were operated by ORIF with LCP plating, 24\% subjects were operated by LCP Plating plus CC screw and $20 \%$ were operated by bicondylar plating. Yu et al., Prasad et al., Zhang et al., Oh et al., Barei et al., and Barei et al., all did different studies and concluded that double plate fixation technique in high-energy Schatzker V and VI tibial plateau fractures via a 2 -incision technique is a feasible treatment option for bicondylar and complex tibial plateau fractures and this is matching our findings $[5,6,7,8,9,10]$

Infection was commonest early complication encountered in $2(8 \%)$ subjects and type VI fracture. However, Infection was 
superficial \& responded to antibiotics treatment. None of them had developed deep infection. Among late complications $4(16 \%)$ had developed stiffness which was found 1 in type V and 3 in type VI fracture type. Non union was found in $2(8 \%)$ subjects with type VI fracture. Study by Nabil A et al. ${ }^{[11]}$ found that infection rate was among $4.3 \%$ and non union was among $1.7 \%$ subjects.

\section{References}

1. Watson JJ, Wiss AD. Rockwood and Green's fractures in adults: Fractures [2] of the proximal tibia and fibula. Bucholz RW and Heckman JD Ed. 5th ed. Philadelphia: Lip-pincott Williams and Wilkins. 2001; 2:1799-1839.

2. Arumugam S, Arumugam V, Raviraman V. To analyze the functional outcome of proximal tibial fractures treated with minimally invasive percutaneous plate osteosynthesis technique. Int J Res Orthop. 2017; 3:120510.

3. Aseri MK, Singh V, Sharma PK. Functional outcome of proximal tibial fracture treated surgically using locking compression plate. Int J Res Orthop. 2018; 4:400-5.

4. Rohra N, Suri H, Gangarde K. Outcome of Schatzker Type V and VI Tibial Plateau Fracture Treatment with Dual Plates. Journal of Clinical and Diagnostic Research. 2016; 10(5):RC05-RC10.

5. Yu Z, Zheng L, Zhang Y, Li J, Ma B. Functional and radiological evaluations of high energy tibial plateau fractures treated with double-buttress plate fixation. Eur J Med Res. 2009; 14(5):200-05.

6. Prasad GT, Kumar TS, Kumar RK, Murthy GK, Sundaram N. Functional outcome of Schatzker type V and VI tibial plateau fractures treated with dual plates. Indian J Orthop. 2013; 47(2):188-94.

7. Zhang Y, Fan D, Ma B, Sun S. Treatment of complicated tibial plateau fractures with dual plating via a 2 -incision technique. Orthopedics. 2012; 35(3):e359-64.

8. Oh CW, Oh JK, Kyung HS, Jeon IH, Park BC, Min WK et al. Double plating [of unsta-ble proximal tibial fractures using minimally invasive percutaneous osteosynthesis tech-nique. Acta Orthop. 2006; 77(3):52430 .

9. Barei DP, Nork SE, Mills WJ, Henley MB, Benirschke SK. Complications associated with internal fixation of high-energy bicondylar tibial plateau fractures utilizing a two-incision technique. J Orthop Trauma. 2004; 18(10):649-57.

10. Barei DP, Nork SE, Mills WJ, Coles CP, Henley MB, Benirschke SK. Functional out-comes of severe bicondylar tibial plateau fractures treated with dual incision and medial and lateral plates. J Bone Joint Surg Am. 2006; 88(8):1713-21.

11. Nabil A Ebraheim et al. Open reduction internal fixation of 117 tibial plateau fractures. University of Ohio, Spotlight hip and knee DEC. 2004; 27:12p.

12. Schatzkar J, Mc Broom R, Bruce D. The tibial plateau fractures-Toronto experience. Clin Orthop. 1979; 138:94. 